\title{
Results of surgical intervention for p-stage IIIA (N2) non- small cell lung cancer: Acceptable prognosis predicted by complete resection in patients with single N2 disease with primary tumor in the upper lobe
}

\author{
Masayoshi Inoue, $\mathrm{MD}, \mathrm{PhD}^{\mathrm{a}}$ \\ Noriyoshi Sawabata, MD, $\mathrm{PhD}^{\mathrm{a}}$ \\ Shin-ichi Takeda, MD, $\mathrm{PhD}^{\mathrm{a}}$ \\ Mitsunori Ohta, MD, $\mathrm{PhD}^{\mathrm{b}}$ \\ Yuko Ohno, PhD ${ }^{\mathrm{c}}$ \\ Hajime Maeda, MD, $\mathrm{PhD}^{\mathrm{a}}$
}

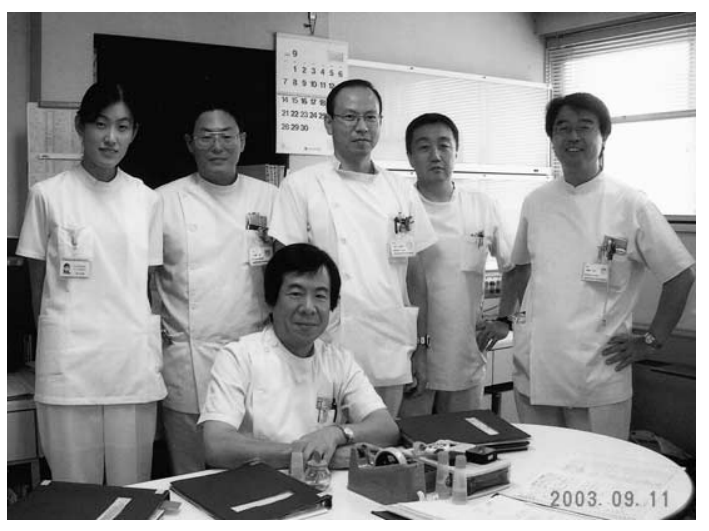

From the Department of Thoracic Surgery, ${ }^{\text {a }}$ Toneyama National Hospital, Osaka, Japan, and the Departments of General Thoracic Surgery $^{\mathrm{b}}$ and Mathematical Health Science, ${ }^{\mathrm{c}}$ Osaka University Graduate School of Medicine, Osaka, Japan.

Received for publication June 26, 2003; revisions received Aug 14, 2003; accepted for publication Sept 9, 2003.

Address for reprints: Masayoshi Inoue, MD, Department of Surgery, Toneyama National Hospital, Toneyama 5-1-1, Toyonaka-city 560-8552, Osaka, Japan (E-mail: masayoshinoue@hotmail.com).

J Thorac Cardiovasc Surg 2004;127:1100-6

$0022-5223 / \$ 30.00$

Copyright (C) 2004 by The American Association for Thoracic Surgery

doi:10.1016/j.jtcvs.2003.09.012
Objectives: Non-small cell lung cancer with mediastinal lymph node involvement is a heterogeneous entity different from single mediastinal lymph node metastasis to multiple nodes or extranodal disease. The objective of this study was to identify the subpopulation of patients with N2 disease who can benefit from surgical intervention.

Methods: We reviewed 219 consecutive patients with N2 non-small cell lung cancer treated with a thoracotomy between November 1980 and June 2002 and retrospectively analyzed 154 of those who had p-stage IIIA disease and underwent a complete resection. Age, sex, side (right or left), histology, location (upper or middle-lower lobe), tumor size, c-N factor, and N2 level (single or multiple) were used as prognostic variables.

Results: The 3- and 5-year survivals were $45.3 \%$ and $28.1 \%$, respectively, in patients with p-stage IIIA (N2) disease. Survival for those with single $\mathrm{N} 2$ non-small cell lung cancer was significantly better than in those with multiple N2 disease $(P=.0001)$, and patients with a tumor in the upper lobe showed a significantly longer survival than those with middle-lower lobe involvement $(P=$ .0467). The 3- and 5-year survivals for patients with single N2 disease with a primary tumor in the upper lobe were $74.9 \%$ and $53.5 \%$, respectively. A multivariate analysis with Cox regression identified 5 predictors of better prognosis: younger age, squamous cell carcinoma as determined by histology, primary tumor location in the upper lobe, c-N0 status, and a single station of mediastinal node metastasis.

Conclusion: Our results suggest that of the heterogeneity of N2 diseases, patients with single N2 disease with non-small cell lung cancer in the upper lobe are good candidates for pulmonary resection.

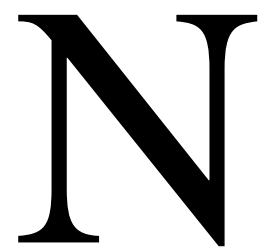

on-small cell lung cancer (NSCLC) with ipsilateral mediastinal lymph node metastasis is generally considered to be a locally advanced disease resulting in a poor outcome, although these patients can be divided into heterogeneous subpopulations, such as those with bulky extranodal metastases and those with either multiple or single N2 involvement. Among these patients, a proportion of patients with $\mathrm{N} 2$ disease, including surgically discovered patients with positive nodes, have been treated with pulmonary resection. The overall 5-year survival in patients with $\mathrm{N} 2$ disease who underwent a curative resection has been 
reported to range from $19 \%$ to $36 \%$; however, most retrospective studies of surgical results of treated patients with N2 NSCLC were highly selective. ${ }^{1}$ Furthermore, several prognostic factors have recently been defined by historical studies, which have shown that complete resection, single mediastinal node metastasis, c-N0-1, low p-T factor, and small tumor size are predictors of better prognosis in patients with N2 NSCLC. ${ }^{2-5}$ However, the type of patients with N2 NSCLC who can benefit most from a thoracotomy has not been clarified. We retrospectively studied patients with N2 NSCLC treated at our institute by analyzing prognostic factors to identify subpopulations with good operative indications.

\section{Patients and Methods \\ Patients}

The records of all 219 patients with NSCLC who underwent a thoracotomy and were confirmed to have positive mediastinal nodes between November 1980 and June 2002 at Toneyama National Hospital, Osaka, Japan, were reviewed. Three patients died of postoperative complications and were excluded from the present study. In principle, we considered patients with single N2 disease to be resectable and those with extranodal or bulky mediastinal node involvement or multiple N2 disease to be inoperable. Thus 163 patients underwent a complete resection (154 for p-stage IIIA, 8 for p-stage IIIB, and 1 for p-stage IV), and an incomplete resection and exploratory thoracotomy were performed in 28 patients for each.

In the present study we focused on the 154 patients with $\mathrm{p}$-stage IIIA (N2) disease treated with a complete resection (Table 1). Follow-up was complete in 131 patients, and the median time for follow-up of all patients was 111.2 months. The mediastinal lymph node was pathologically confirmed to be metastatic in all patients who underwent a pulmonary resection. Preoperative diagnosis was performed by using chest radiography and computed tomographic (CT) imaging, as well as fiberoptic bronchoscopy for pulmonary nodules. Mediastinal nodes larger than $1 \mathrm{~cm}$ in the short axis were defined as clinical N2 disease. A mediastinoscopy was carried out in selected patients because of protocol setting or in some with suspected c-N2 disease before induction therapy, although not routinely. Brain $\mathrm{CT}$ or magnetic resonance imaging results, as well as those from upper abdominal CT and bone scintigraphy examinations, were used to detect distant metastases. Postoperative staging was performed according to the 1997 TNM classification. ${ }^{6}$ All dissected hilar and mediastinal lymph nodes were pathologically examined and classified according to anatomic location by using Naruke's numbering system. ${ }^{7}$ Complete resection was defined as that without a macroscopic residual lesion and with microscopic free margins around the tumor site. Patients with pleural dissemination or malignant pleural effusion were defined as having an incomplete resection, even if there was no macroscopic residual lesion after the pulmonary resection. Induction and adjuvant therapy were performed in 22 and 46 patients, respectively. Eighty-six patients were treated with surgical intervention alone. All patients treated with induction therapy had been given a diagnosis of c-N2 disease on the basis of CT scanning or mediastinoscopy. As for lymph node dissection, in patients with a tumor
TABLE 1. Characteristics of 154 patients with p-stage IIIA (N2) NSCLC (from our patient database: November 1980June 2002)

\begin{tabular}{|c|c|}
\hline Age (y) & 38-80 (median, 62) \\
\hline \multicolumn{2}{|l|}{ Sex } \\
\hline Female & 55 \\
\hline Male & 99 \\
\hline \multicolumn{2}{|l|}{$\mathrm{c}-\mathrm{N}$ factor } \\
\hline C-NO & 71 \\
\hline $\mathrm{c}-\mathrm{N} 1$ & 20 \\
\hline $\mathrm{c}-\mathrm{N} 2$ & 60 \\
\hline $\mathrm{c}-\mathrm{N} 3$ & 3 \\
\hline \multicolumn{2}{|l|}{ N2 level } \\
\hline Single & 75 \\
\hline Multiple & 79 \\
\hline \multicolumn{2}{|l|}{ Histology } \\
\hline $\mathrm{Ad}$ & 101 \\
\hline $\mathrm{Sq}$ & 41 \\
\hline $\mathrm{La}$ & 11 \\
\hline $\mathrm{Ad}-\mathrm{Sq}$ & 1 \\
\hline \multicolumn{2}{|l|}{ Side } \\
\hline Right & 99 \\
\hline Left & 55 \\
\hline \multicolumn{2}{|l|}{ Treatment } \\
\hline Surgical intervention alone & 86 \\
\hline Surgical intervention + CT & 39 \\
\hline Surgical intervention $+\mathrm{RT}$ & 11 \\
\hline $\begin{array}{l}\text { Surgical intervention }+ \text { CRT } \\
\text { (Induction therapy, 22) }\end{array}$ & 18 \\
\hline \multicolumn{2}{|l|}{ Mode } \\
\hline Pneumonectomy & 25 \\
\hline Lobectomy & 126 \\
\hline Partial resection & 3 \\
\hline
\end{tabular}

$A d$, Adenocarcinoma; $S q$, squamous cell carcinoma; La, large cell carcinoma; $A d-S q$, adenosquamous cell carcinoma; $C T$, chemotherapy; $R T$, radiation therapy; $C R T$, chemoradiation therapy.

in the right upper-middle lobe, the superior mediastinal, paratracheal, pretracheal, tracheobronchial, and subcarinal nodes were removed. In those with a tumor in the left upper lobe, the tracheobronchial, subaortic, para-aortic, and subcarinal nodes were removed. In addition to these nodes, paraesophageal and pulmonary ligament nodes were dissected in patients with tumors in both lower lobes. The pretracheal node in patients with a left-side tumor and the anterior and posterior mediastinal nodes were optional.

Patients were evaluated on the basis of age, sex, side (right or left), histology, tumor location (upper lobe or middle-lower lobe), largest diameter of the tumor, $\mathrm{c}-\mathrm{N}$ factor, and metastatic mediastinal lymph node level (single or multiple) to determine prognostic factors.

\section{Statistical Analysis}

Overall survival denotes the period from the date of initial treatment. The probability of survival was calculated by using the Kaplan-Meier method. ${ }^{8}$ The prognostic influence of variables on survival was analyzed by using a log-rank test and a Cox proportional hazards model. ${ }^{9}$ 


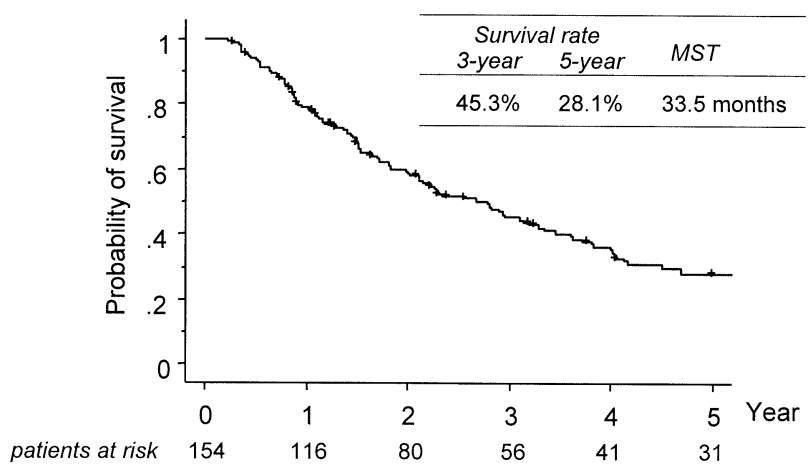

Figure 1. Overall survival for 154 patients with p-stage IIIA (N2) NSCLC who underwent a complete resection.

\section{Results}

The 3- and 5-year survivals for patients with p-stage IIIA (N2) disease who underwent a complete resection were $45.3 \%$ and $28.1 \%$, respectively (Figure 1 ). The 5-year survivals for patients with c-N0, c-N1, and c-N2-3 disease were $45.5 \%, 26.5 \%$, and $12.0 \%$, respectively. The survival of patients with c-N0 disease was significantly better than that of patients with $\mathrm{c}-\mathrm{N} 2-3$ disease $(P<.0001)$. No significant difference was found between the c-N0 and c-N1 groups $(P=.2249)$. Median survival time (MST) was 49.5 months for the c-N0 group, 37.7 months for the c-N1 group, and 17.9 months for the c-N2-3 group. Thus preoperative c-N factor, determined with a chest CT scan, was able to predict prognosis because surgically discovered patients with $\mathrm{N} 2$ disease had a better outcome than those given a preoperative diagnosis of c-N2 disease.

We also assessed survival by histologic type. The 5-year survival and MST were 39.6\% and 46 months, respectively, for patients with squamous cell carcinoma; $23.9 \%$ and 30.6 months, respectively, for patients with adenocarcinoma; and $18.2 \%$ and 15.4 months, respectively, for patients with large cell carcinoma. We found a significant difference between patients with squamous cell carcinoma and those with large cell carcinoma $(P=.0200)$. Furthermore, the survival for patients with squamous cell carcinoma showed a tendency to be better than that for patients with adenocarcinoma, although the difference was not significant $(P=.0826)$.

In the present study a single metastasis in the mediastinal node was retrospectively found in 75 patients, and multiple metastases were found in 79 patients. The 5-year survival and MST for patients with single N2 disease were $42.7 \%$ and 48.5 months, respectively, which were both significantly better than those seen in the multiple N2 group, which had a 5-year survival of $15.5 \%$ and MST of 23.6 months (Figure 2). The outcome for patients with multiple N2 disease who underwent a complete resection was poor, although it was better than that for patients treated with an incomplete resection, who had an MST of 14.2, or those

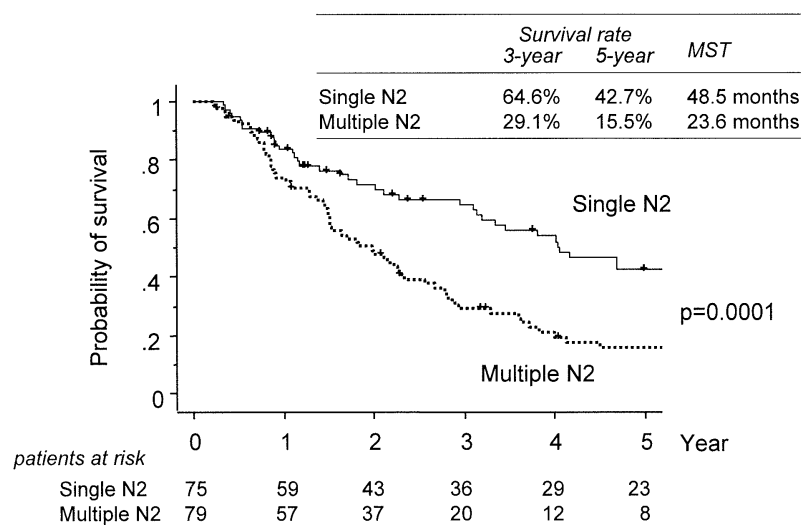

Figure 2. Probability of survival for patients with stage IIIA (N2) NSCLC who underwent a complete resection according to N2 level. Survival for those with single N2 disease was significantly better than for those with multiple N2 disease.

with exploratory thoracotomy, who had an MST of 13.9 months.

We speculated that patients with single N2 disease with a primary lesion in the upper lobe tended to survive longer than patients with other types of N2 disease, and therefore we studied survival difference on the basis of tumor location. The 5-year survival and MST for patients with a tumor in the upper lobe were $34.6 \%$ and 37.7 months, respectively, which were significantly better than those for patients with a lesion in the middle-lower lobe (Figure 3).

When analyzed according to both N2 level and tumor location (upper or middle-lower lobe), the 3- and 5-year survivals were $74.9 \%$ and $53.5 \%$, respectively, and MST was 124 months in patients with single N2 disease and an upper lobe primary tumor, which were significantly better than the results for patients with multiple N2 disease (Figure 4). Metastatic mediastinal lymph nodes in single $\mathrm{N} 2$ NSCLC are listed in Table 2 according to tumor location. Lesions in the upper lobe were mainly metastasized to the upper mediastinal nodes, and those in the middle-lower lobe were mainly metastasized to the subcarinal nodes. We further analyzed patients with single N2 disease with an upper lobe lesion to investigate outcome by side. The 5-year survival was $70.0 \%$ in patients with a left upper lobe lesion involving a subaortic or para-aortic lymph node $(\mathrm{n}=10)$ and $55.4 \%$ in patients with a right upper lobe lesion involving a superior mediastinal, paratracheal, pretracheal, or tracheobronchial node $(\mathrm{n}=22, P=.5095)$. Although the number of patients was small, the 5-year survival of those with a left upper lobe lesion was extremely good.

A univariate analysis using the variables listed in Table 3 showed that histology (large cell carcinoma/squamous cell carcinoma), location (middle-lower lobe/upper lobe), tumor diameter, c-N factor (c-N2-3/c-N0), and N2 level (multiple/ single) were significant prognostic factors. Patient age also 


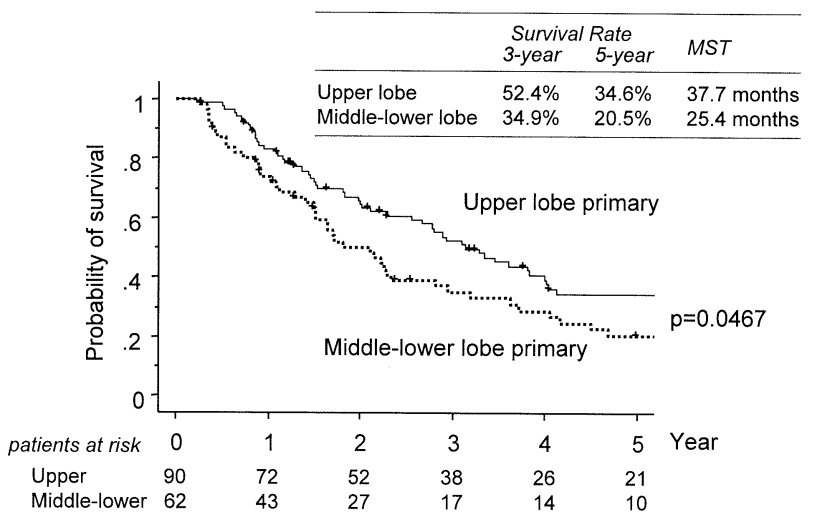

Figure 3. Probability of survival for patients with stage IIIA (N2) NSCLC who underwent a complete resection according to primary tumor location. Two patients with a tumor in the left main bronchus were excluded from these results. Patients with a tumor in the upper lobe showed a significantly longer survival compared with that in those with a tumor in the middle-lower lobe.

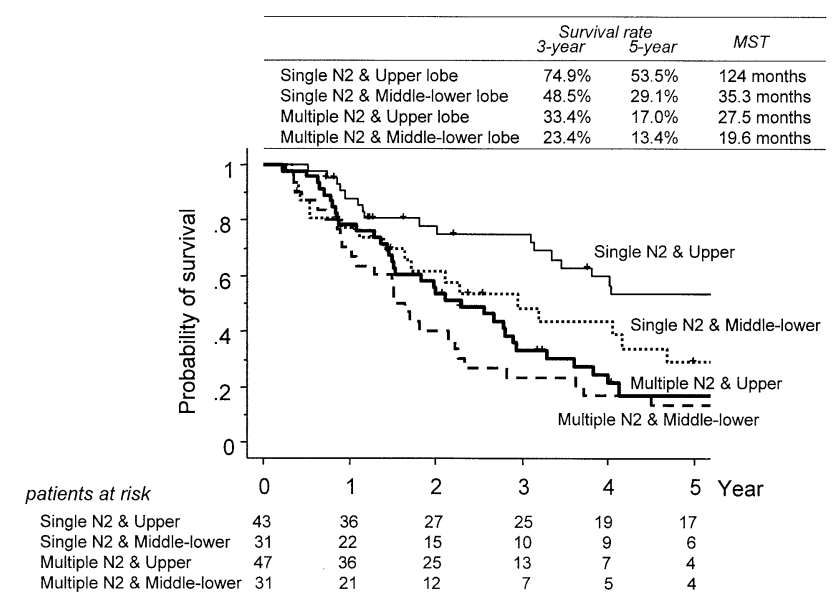

Figure 4. Probability of survival for patients with stage IIIA (N2) NSCLC who underwent a complete resection according to both N2 level and tumor location. Two patients with a tumor in the left main bronchus were excluded from these results. The survival of patients with single N2 disease and upper lobe primary involvement was significantly better compared with that of those with multiple N2 disease and upper lobe primary involvement $(P=$ .0010) or those with multiple N2 disease and middle-lower lobe primary involvement $(P<.0001)$ and also tended to be better than survival in patients with single N2 disease and middle-lower lobe primary involvement $(P=.0900)$.

showed a prognostic factor trend, although it was not significant, whereas sex and tumor side did not have a prognostic effect. Using these variables, we also performed a multivariate analysis (Table 4). We found that age, histology (both adenocarcinoma and large cell carcinoma/squa-
TABLE 2. Prevalence of mediastinal positive lymph nodes according to location of the primary lesion in patients with single N2 p-stage IIIA NSCLC

\begin{tabular}{ccccc}
\hline Station no. & RUL & LUL & RMLL & LLL \\
\hline 1 & 1 & & 1 & \\
2 & 2 & & 1 & 1 \\
3 & 13 & 1 & 2 & \\
$3 a$ & 3 & 1 & 1 & \\
$3 p$ & & 1 & 2 & \\
4 & 6 & 1 & & 1 \\
5 & & 7 & 13 & \\
6 & 2 & 1 & 1 & 1 \\
7 & 1 & & & 2 \\
8 & & & & \\
9 & & & & \\
\hline
\end{tabular}

Station, Mediastinal lymph node station according to Naruke's numbering system7; $R U L$, right upper lobe; $L U L$, left upper lobe; $R M L L$, right middlelower lobe; $L L L$, left lower lobe.

TABLE 3. Potential prognostic factors in patients with $\mathrm{p}$ stage IIIA (N2) NSCLC by univariate analysis

\begin{tabular}{lccr}
\hline Variables & $\begin{array}{c}\text { Hazard } \\
\text { ratio }\end{array}$ & $\mathbf{9 5 \%} \mathbf{C L}$ & $\boldsymbol{P}$ value \\
\hline Age & 1.024 & $0.999-1.050$ & .0618 \\
Sex (male/female) & 1.198 & $0.790-1.817$ & .3958 \\
Side (right/left) & 1.055 & $0.700-1.590$ & .7975 \\
Histology & & & \\
$\quad$ Sq & 1.000 & & \\
$\quad$ Ad & 1.531 & $0.951-2.464$ & .0794 \\
La & 2.517 & $1.201-5.273$ & .0145 \\
Location (ML/U) & 1.490 & $1.003-2.216$ & .0484 \\
Tumor size & 1.153 & $1.011-1.315$ & .0331 \\
C-N & & & \\
$\quad$ N0 & 1.000 & & \\
$\quad$ N1 & 1.453 & $0.779-2.709$ & .2399 \\
$\quad$ N2-3 & 2.807 & $1.812-4.348$ & $<.0001$ \\
N2 (multiple/single) & 2.189 & $1.455-3.293$ & .0002 \\
\hline
\end{tabular}

$C L$, Confidence limit; $S q$, squamous cell carcinoma; $A d$, adenocarcinoma; $L a$, large cell carcinoma; $M L$, middle-lower lobe; $U$, upper lobe.

mous cell carcinoma), location (middle-lower lobe/upper lobe), c-N factor (c-N2-3/c-N0), and N2 level (multiple/ single) were independent prognostic predictors.

\section{Discussion}

Surgical indication for a patient with N2 NSCLC is generally marginal because of local advancement and poor prognosis; however, it has recently been reported that a proportion of patients with N2 NSCLC might have a good chance of survival after a pulmonary resection. ${ }^{2,4,5,10}$ Although several potential prognostic factors have been tested, it is still unclear which of these patients might benefit most from surgical intervention. In the present study we retrospectively analyzed patients with p-stage IIIA (N2) disease in 
TABLE 4. Potential prognostic factors in patients with $\mathbf{p}$ stage IIIA (N2) NSCLC by multivariate analysis

\begin{tabular}{lccr}
\hline Variables & $\begin{array}{c}\text { Hazard } \\
\text { ratio }\end{array}$ & $\mathbf{9 5 \%} \mathbf{C L}$ & $\boldsymbol{P}$ value \\
\hline Age & 1.034 & $1.009-1.060$ & .0066 \\
Sex (male/female) & 1.423 & $0.901-2.247$ & .1306 \\
Side (right/left) & 1.015 & $0.657-1.568$ & .9469 \\
Histology & & & \\
$\quad$ Sq & 1.000 & & \\
$\quad$ Ad & 3.048 & $1.710-5.432$ & .0002 \\
La & 7.328 & $3.083-17.416$ & $<.0001$ \\
Location (ML/U) & 1.578 & $1.030-2.419$ & .0362 \\
Tumor size & 1.111 & $0.955-1.293$ & .1713 \\
C-N & & & \\
$\quad$ N0 & 1.000 & & \\
$\quad$ N1 & 1.563 & $0.764-3.194$ & .2210 \\
$\quad$ N2-3 & 3.028 & $1.842-4.978$ & $<.0001$ \\
N2 (multiple/single) & 1.883 & $1.208-2.936$ & .0052 \\
\hline
\end{tabular}

See abbreviations in Table 3.

our institute to identify subpopulations suitable for pulmonary resection, and our results indicated that patients with single N2 involvement with NSCLC in the upper lobe would be good candidates for a possible curative resection.

We expected that survival for patients with single N2 disease would be significantly better than that for those with multiple N2 disease (Figure 2) because the latter is definitively an advanced status, and other reports have shown a significantly better survival in such patients with N2 NSCLC. ${ }^{2-5,11-17}$ Furthermore, Luzzi and associates ${ }^{18}$ noted that patients with less than $50 \%$ lymph node infiltration, which was calculated as the ratio of positive nodes to all dissected mediastinal nodes, showed a significantly more favorable outcome. We believe that those results are important when considering surgical indications in patients with N2 NSCLC because patients with single and multiple N2 disease are heterogeneous subpopulations that have very different prognoses. The 5-year survival of $42.7 \%$ and MST of 48.5 months for patients with single N2 NSCLC in the present study suggest that patients with less advanced N2 NSCLC could be cured by, or at least benefit from, surgical resection.

It was interesting to note differences in survival of patients with N2 NSCLC by location of the primary tumor (upper vs middle-lower lobe, Figure 3). When analyzing only patients with single $\mathrm{N} 2$ disease with a tumor in the upper lobe, the 5-year survival was 53.5\% (Figure 4), which was somewhat surprising because it was similar or better than that reported for N1 NSCLC. ${ }^{6,19}$ Because we found no survival difference by location of the primary lesion in patients with p-N0 or pN1 NSCLC in our institute (data not shown), a better prognosis for patients with an upper lobe lesion was an interesting characteristic of N2 NSCLC disease. Ichinose and colleagues ${ }^{5}$ pointed out the relationship between primary tumor location and metastatic N2 station (ie, there were frequent metastases from the right upper lobe at no. 3, from the left upper lobe at no. 5, and from the right middle-lower and left lower lobes at no. 7). In the present study we also observed a similar tendency of prevalent positive nodes (Table 2). Furthermore, the outcome of N2 NSCLC associated with upper mediastinal lymph node involvement has been reported to be better compared with that with lower mediastinal metastasis. ${ }^{10,11,20}$ Thus we suppose that there is a relationship between upper mediastinal node involvement and a tumor located in the upper lobe and, furthermore, that this particular subpopulation could benefit from complete resection. We also propose that a prethoracotomy evaluation by tumor location provides more information to predict the prognosis of patients than that by site of metastatic node.

Patients with c-N0 status showed significantly better survival than those with c-N2-3 status (Tables 3 and 4). This result has also been shown in other studies, and c-N diagnosis using chest $\mathrm{CT}$ scanning is an important reference factor. ${ }^{2,4,10,15}$ However, it has been reported that lymph node size detected on the basis of CT is not reliable for an evaluation of metastasis. ${ }^{21}$ Therefore we propose that a more accurate evaluation for mediastinal lymph nodes is necessary. We recently adopted fiberscopic transbronchial needle aspiration, mediastinoscopy, and/or exploratory thoracoscopy for preoperative evaluation of patients with c-N2 disease given a diagnosis on the basis of chest CT scanning. Although fluorodeoxyglucose-positron emission tomography might be useful in the evaluation of mediastinal nodes, the accuracy is still less than that of mediastinoscopy. ${ }^{22,23}$ Thus we believe that accurate preoperative staging with these examinations can contribute to the decision of surgical indication and better prognosis for patients with less advanced N2 NSCLC.

Univariate and multivariate analyses showed that histologic type was one of the prognostic factors in completely resected stage IIIA (N2) NSCLC (Tables 3 and 4). Furthermore, the outcome of patients with squamous cell carcinoma was significantly better than that of those with adenocarcinoma or large cell carcinoma in the present study. A better survival in patients with squamous cell carcinoma compared with those with nonsquamous cell carcinoma was previously mentioned by Vansteenkiste and colleagues ${ }^{15}$ and Goldstraw and associates ${ }^{16}$ with significant differences, whereas Suzuki and coworkers, ${ }^{2}$ Martini and colleagues, ${ }^{10}$ and Nakanishi and associate ${ }^{20}$ found no significant results by histologic type. In their studies Suzuki and coworkers ${ }^{2}$ and Nakanishi and associates ${ }^{20}$ compared adenocarcinoma with other histologic findings, which were mainly squamous cell carcinoma; however, they also included large cell carcinoma and adenosquamous cell carcinoma, which are generally considered to be more malignant in patients with 
NSCLC. ${ }^{24}$ In contrast to our report, Martini and colleagues ${ }^{10}$ did not perform a multivariate analysis. From their and our results, we considered that squamous cell carcinoma histology is a better prognostic predictor in addition to single $\mathrm{N} 2$ status and tumor location in the upper lobe in patients with p-stage IIIA (N2) NSCLC.

A portion of the patients (22/154) in the present study were treated with induction therapy, and their outcome also depended on the status of persistent N2. ${ }^{25-27}$ Regarding the level of mediastinal node metastasis, Sawabata and cowork$\mathrm{ers}^{28}$ recently clarified that the chance of 5-year survival was $54 \%$ for single-level and $11 \%$ for multiple-level persistent $\mathrm{N} 2$ disease after induction therapy. These findings are similar to the results in the present study.

The Toronto group reported that patients with a lesion in the right upper lobe frequently had upper mediastinal node involvement, suggesting a direct lymphatic drainage mechanism from the primary tumor to the right paratracheal or tracheobronchial lymph nodes. ${ }^{29}$ Later, they also reported that good prognosis could be predicted after complete resection in patients with a primary tumor in the left upper lobe associated with only subaortic node involvement. ${ }^{30}$ Our results are compatible with the results of those reports, and we additionally clarified 2 new findings in the present study, which were that single N2 involvement, upper lobe tumor, and histology of squamous cell carcinoma were better independent prognostic predictors by means of multivariate analysis in patients with N2 NSCLC, and the 5 -year survival of patients with single N2 NSCLC with an upper lobe tumor was similar to that of patients with N1 NSCLC and better than results of previous reports.

In summary, younger age, squamous cell carcinoma histology, tumor in the upper lobe, single N2 NSCLC, and c-NO status on a chest CT scan were better independent prognostic predictors. Among the heterogeneous entities, we considered that a patient with a single N2 NSCLC in the upper lobe is the best candidate for pulmonary resection.

\section{References}

1. Detterbeck FC, Jones DR. Surgical treatment of stage IIIA (N2) non-small cell lung cancer. In: Detterbeck FC, Rivera MP, Socinski MA, Rosenman JG, editors. Diagnosis and treatment of lung cancer. Philadelphia: W. B. Saunders; 2001. p. 244-56.

2. Suzuki K, Nagai K, Yoshida J, Nishimura M, Takahashi K, Nishiwaki $\mathrm{Y}$. The prognosis of surgically resected N2 non-small cell lung cancer: the importance of clinical N status. J Thorac Cardiovasc Surg. 1999; 118:145-53.

3. Régnard JF, Magdeleinat P, Azoulay D, Dartevelle P, Deneuville M, Rojas-Miranda A, et al. Results of resection for bronchogenic carcinoma with mediastinal lymph node metastases in selected patients. Eur J Cardiothorac Surg. 1991;5:583-7.

4. Andre F, Grunenwald D, Pignon J-P, Dujon A, Pujol JL, Brichon PY, et al. Survival of patients with resected N2 non-small cell lung cancer: evidence for a subclassification and implications. J Clin Oncol. 2000; 18:2981-9.

5. Ichinose Y, Kato H, Koike T, Tsuchiya R, Fujisawa T, Shimizu N, et al. Completely resected stage IIIA non-small cell lung cancer: the significance of primary tumor location and $\mathrm{N} 2$ station. $J$ Thorac Cardiovasc Surg. 2001;122:803-8.

6. Mountain CF. Revisions in the international system for staging lung cancer. Chest. 1997;111:1710-7.

7. Naruke T, Suemasu K, Ishikawa S. Lymph node mapping and curability at various levels of metastasis in resected lung cancer. J Thorac Cardiovasc Surg. 1978;76:832-9.

8. Kaplan EL, Meier P. Nonparametric estimation from incomplete observations. J Am Stat Assoc. 1958;53:457-81.

9. Cox DR. Regression models and life-tables. $J R$ Stat Soc Series. 1972;34:187-220.

10. Martini N, Flehinger BJ, Zaman MB, Beattie EJ Jr. Results of resection in non-oat cell carcinoma of the lung with mediastinal lymph node metastases. Ann Surg. 1983;198:386-97.

11. Maggi G, Casadio C, Cianci R, Molinatti M, Filosso PL, Nicolosi M, et al. Results of surgical resection of stage IIIA (N2) non-small cell lung cancer, according to the site of the mediastinal metastases. Int Surg. 1993;78:213-7.

12. Riquet M, Manac'h D, Saab M, Le Pimpec-Barthes F, Dujon A, Debesse B. Factors determining survival in resected N2 lung cancer. Eur J Cadiothorac Surg. 1995;9:300-4.

13. Miller DL, McManus KG, Allen MS, Ilstrup DM, Deschamps C, Trastek VF, et al. Results of surgical resection in patients with N2 non-small cell lung cancer. Ann Thorac Surg. 1994;57:1095-101.

14. Watanabe Y, Hayashi Y, Shimizu J, Oda M, Iwa T. Mediastinal nodal involvement and the prognosis of non-small cell lung cancer. Chest. 1991;100:422-8

15. Vansteenkiste JF, De Leyn PR, Deneffe GJ, Stalpaert G, Nackaerts KL, Lerut TE, et al. Survival and prognostic factors in resected N2 non-small cell lung cancer: a study of 140 cases. Ann Thorac Surg. 1997;63:1441-50.

16. Goldstraw P, Mannam GC, Kaplan DK, Michail P, Shields TW. Surgical management of non-small-cell lung cancer with ipsilateral mediastinal node metastasis (N2 disease). J Thorac Cardiovasc Surg. 1994;107:19-28.

17. Conill C, Astudillo J, Verger E. Prognostic significance of metastases to mediastinal lymph node levels in resected non-small cell lung carcinoma. Cancer. 1993;72:1199-202.

18. Luzzi L, Paladini P, Ghiribelli C, Voltolini L, Di Bisceglie M, D’Agata A, et al. Assessing the prognostic value of the extent of mediastinal lymph node infiltration in surgically-treated non-small cell lung cancer (NSCLC). Lung Cancer. 2000;30:99-105.

19. Naruke T, Goya T, Tsuchiya R, Suemasu K. Prognosis and survival in resected lung carcinoma based on the new international staging system. J Thorac Cardiovasc Surg. 1988;96:440-7.

20. Nakanishi R, Osaki T, Nakanishi K, Yoshino I, Yoshimatsu T, Watanabe $\mathrm{H}$, et al. Treatment strategy for patients with surgically discovered N2 stage IIIA non-small cell lung cancer. Ann Thorac Surg. 1997;64:342-8.

21. Prenzel KL, Mönig SP, Sinning JM, Baldus SE, Brochhagen H-G, Schneider PM, et al. Lymph node size and metastatic infiltration in non-small cell lung cancer. Chest. 2003;123:463-7.

22. Kernstine KH, McLaughlin KA, Menda Y, Rossi NP, Kahn DJ, Bushnell DL, et al. Can FDG-PET reduce the need for mediastinoscopy in potentially resectable nonsmall cell lung cancer? Ann Thorac Surg. 2002;73:394-402.

23. Ryu J-S, Choi NC, Fischman AJ, Lynch TJ, Mathisen DJ. FDG-PET in staging and restaging non-small cell lung cancer after neoadjuvant chemoradiotherapy: correlation with histopathology. Lung Cancer. 2002;35:179-87.

24. Nakagawa K, Yasumitsu T, Fukuhara K, Shiono H, Kikui M. Poor prognosis after lung resection for patients with adenosquamous carcinoma of the lung. Ann Thorac Surg. 2003;75:1740-4.

25. Okada M, Tsubota N, Yoshimura M, Miyamoto Y, Matsuoka H. Induction therapy for non-small cell lung cancer with involved mediastinal nodes in multiple stations. Chest. 2000;118:123-8.

26. Bueno R, Richards WG, Swanson SJ, Jaklitsch MT, Lukanich JM, Mentzer SJ, et al. Nodal stage after induction therapy for stage IIIA lung cancer determines patient survival. Ann Thorac Surg. 2000;70: $1826-31$. 
27. Martin J, Ginsberg RJ, Venkatraman ES, Bains MS, Downey RJ, Korst $\mathrm{RJ}$, et al. Long-term results of combined-modality therapy in resectable non-small-cell lung cancer. J Clin Oncol. 2002;20:1989-95.

28. Sawabata N, Keller MS, Matsumura A, Kawashima O, Hirono T, Osaka Y, et al. The impact of residual multi-level N2 disease after induction therapy for non-small cell lung cancer. Lung Cancer. 2003; 42:69-77.
29. Pearson FG, DeLarue NC, Ilves R, Todd TR, Cooper JD. Significance of positive superior mediastinal nodes identified at mediastinoscopy in patients with resectable cancer of the lung. J Thorac Cardiovasc Surg. 1982;83:1-11.

30. Patterson GA, Piazza D, Pearson FG, Todd TR, Ginsberg RJ, Goldberg M, et al. Significance of metastatic disease in subaortic lymph nodes. Ann Thorac Surg. 1987;43:155-9.

\section{UN THE MOVE?}

Don't miss a single issue of the journal! To ensure prompt service when you change your address, please photocopy and complete the form below.

Please send your change of address notification at least six weeks before your move to ensure continued service. We regret we cannot guarantee replacement of issues missed due to late notification.

\section{JOURNAL TITLE:}

Fill in the title of the journal here.

\section{OLD ADDRESS:}

Affix the address label from a recent issue of the journal here.

\section{NEW ADDRESS:}

Clearly print your new address here.

Name

Address

City/State/ZIP

\section{COPY AND MAIL THIS FORM TO:}

Elsevier Inc.

Subscription Customer Service

6277 Sea Harbor Dr

Orlando, FL 32887
OR FAX TO:

407-363-9661
OR PHONE:

800-654-2452

Outside the U.S., call

407-345-4000 